\title{
INVESTIGATION OF SOLIDIFICATION BEHAVIOR OF THE Sn-RICH TERNARY Sn-Bi-Zn ALLOYS
}

\author{
S. Mladenović ${ }^{1}$, D. Manasijević ${ }^{1}$, M. Gorgievski ${ }^{1}$, D. Minić ${ }^{2}$, S. Dimitrijević ${ }^{3 *}$ \\ ${ }^{1}$ University of Belgrade, Technical Faculty in Bor, Serbia \\ ${ }^{2}$ University of Priština, Faculty of Technical Sciences, \\ Kosovska Mitrovica, Serbia \\ ${ }^{3}$ Mining and Metallurgy Institute Bor, Bor, Serbia
}

Received 08.02.2017

Accepted 13.03.2017

\begin{abstract}
Solidification properties and microstructure of six as-cast $\mathrm{Sn}-\mathrm{Bi}-\mathrm{Zn}$ alloys with 80 at.\% of $\mathrm{Sn}$ and variable contents of $\mathrm{Bi}$ and $\mathrm{Zn}$ were experimentally investigated using the scanning electron microscopy (SEM) with energy-dispersive X-ray spectroscopy (EDS) and differential scanning calorimetry (DSC). The experimentally obtained results were compared with predicted phase equilibria according to the calculation of phase diagram (CALPHAD) method and by the Scheil solidification simulation.
\end{abstract}

Keywords: $S n-B i-Z n$ system; solidification; SEM-EDS; DSC

\section{Introduction}

The eutectic $\mathrm{Sn}-\mathrm{Zn}$ lead-free solder has been recognized as a possible replacement of $\mathrm{Sn}-\mathrm{Pb}$ due to consideration the environmental concerns and the alpha radiation of impurities of $\mathrm{Pb}[1-4]$. $\mathrm{Sn}-9 \mathrm{Zn}$ eutectic alloy has melting temperature $\left(198{ }^{\circ} \mathrm{C}\right)$ close to that of $\mathrm{Sn}-\mathrm{Pb}$ eutectic alloy $\left(183^{\circ} \mathrm{C}\right)$, and offers better mechanical properties than the conventional $\mathrm{Sn}-\mathrm{Pb}$ solders. The addition of $\mathrm{Bi}$ to the $\mathrm{Sn}-\mathrm{Zn}$ eutectic alloy imparts the superior soldering properties, such as high joining strength, good wettability, and low melting temperature in electronic packaging. Due to the drastic improvement of flux technology for $\mathrm{Sn}-\mathrm{Zn}$ system, the $\mathrm{Sn}-\mathrm{Zn}-\mathrm{Bi}$ solder pastes have been widely applied in many products, i.e., notebook computers, desktop computers, printers, TV tuners, electronic dictionaries, etc.

Although the ternary $\mathrm{Bi}-\mathrm{Sn}-\mathrm{Zn}$ ternary system has been studied extensively $[5,6]$, it seems that there are not many studies focused on the Sn-rich range of

\footnotetext{
* Corresponding author: Silvana Dimitrijević, silvana.dimitrijevic@irmbor.co.rs
} 
composition which is very important for development the lead-free solders. Thus, the aim of this work is experimental investigation of solidification behavior of the as-cast $\mathrm{Sn}$-rich ternary $\mathrm{Sn}-\mathrm{Bi}-\mathrm{Zn}$ alloys. For this purpose, six ternary alloys with the constant content of tin (80 at.\%) were prepared from pure metals and investigated using the SEM-EDS and DSC techniques. The experimentally obtained results were compared with the results of thermodynamic calculation according to the CALPHAD approach.

\section{Experimental Procedure}

Six ternary alloys, with approximately constant atomic percent of Sn (80 at.\%) and variable contents of $\mathrm{Zn}$ and Bi were prepared using $\mathrm{Sn}, \mathrm{Zn}$, and Bi (purity 99.99\%) as the starting materials.

The appropriate weights of elements were melted in an induction furnace under an argon atmosphere. The alloys were melted several times to improve homogeneity. The molten solders in crucible were chill cast in a graphite mold to form the cylindrical ingots of $17 \mathrm{~mm}$ in diameter. As-cast alloys were obtained by cooling in air.

To observe the microstructure of the six as-cast solder alloys, the specimens were polished with $0.05 \mu \mathrm{m} \mathrm{Al}_{2} \mathrm{O}_{3}$ powders and etched with $2 \% \mathrm{HCl}, 3 \% \mathrm{HNO}_{3}$ and $95 \%$ (vol.\%) $\mathrm{C}_{2} \mathrm{H}_{5} \mathrm{OH}$ solution.

The overall compositions and compositions of the present phases in the as-cast specimens were examined by the Scanning Electron Microscopy using JEOL (JSM6460) microscope equipped with the Oxford Instruments Energy Dispersive Spectrometer.

The phase transition temperatures were determined by the SDT Q600 (TA Instruments) simultaneous DSC/TGA analyzer. DSC measurements were done in argon atmosphere, through 2 heating cycles. A heating rate of $5{ }^{\circ} \mathrm{C} / \mathrm{min}$ was employed both for calibration and measurement of the prepared samples.

\section{Thermodynamic Calculation of the Sn-Bi-Zn Phase Equilibria}

Thermodynamic calculation of $\mathrm{Sn}-\mathrm{Bi}-\mathrm{Zn}$ phase equilibria was done according to the calculation of phase diagram (CALPHAD) methodology $[7,8]$ using a set of optimized thermodynamic parameters from Vizdal et al. [6] included in the COST531 database [9]. Calculations were performed by PANDAT software [10].

Fig. 1 shows calculated phase diagrams of the constitutive binary systems. It can be seen that the Bi-Sn and $\mathrm{Sn}-\mathrm{Zn}$ binary systems are simple binary eutectic systems with small mutual solubility of components. In the Bi-Sn binary system eutectic reaction occurs at $138.4{ }^{\circ} \mathrm{C}$, and in the $\mathrm{Sn}-\mathrm{Zn}$ binary system eutectic reaction is at $198.6^{\circ} \mathrm{C}$. The phase diagram of the $\mathrm{Bi}-\mathrm{Zn}$ binary system is more complex comparing to the $\mathrm{Bi}-\mathrm{Sn}$ and $\mathrm{Sn}-\mathrm{Zn}$ binary systems. It includes the liquid immiscibility region and monotectic reaction at $418.3^{\circ} \mathrm{C}$. Temperature of the eutectic reaction is $254.5^{\circ} \mathrm{C}$. 

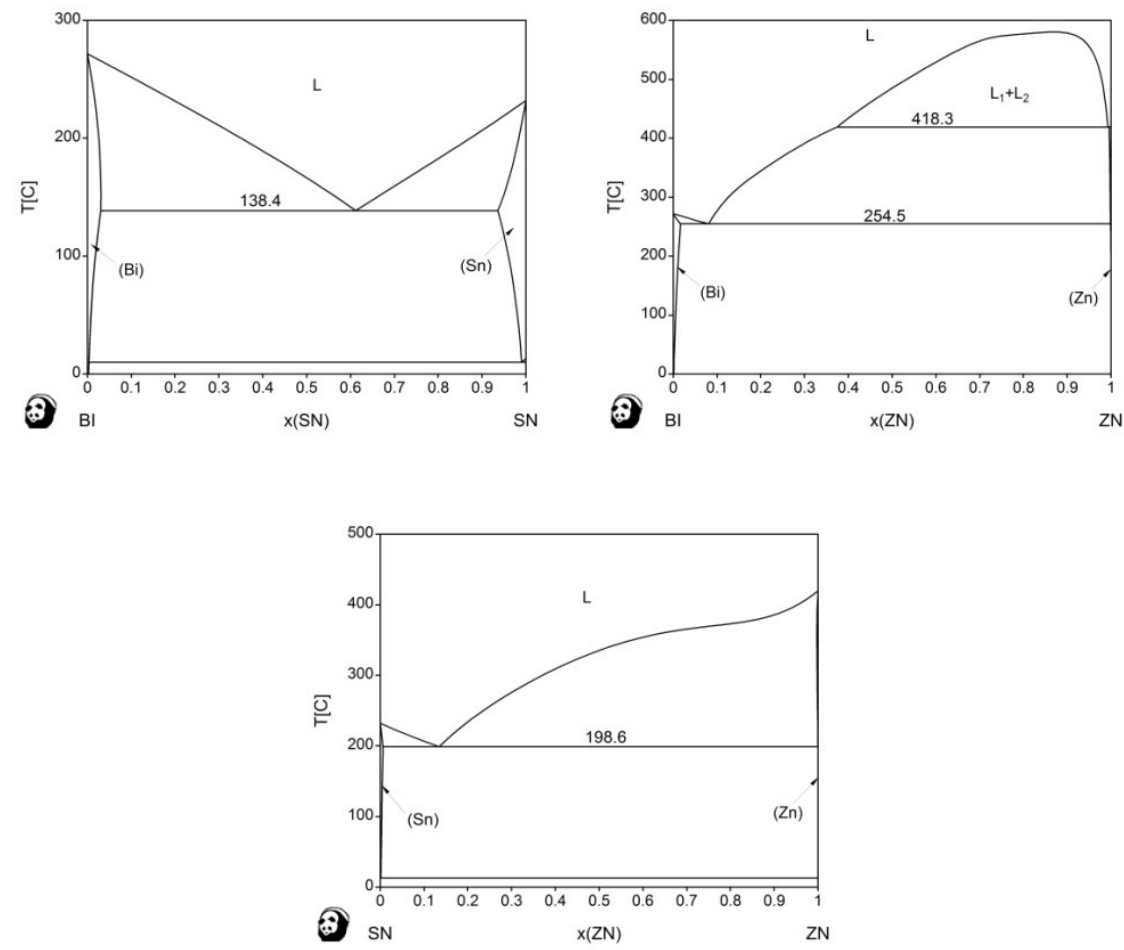

Fig. 1. Calculated phase diagrams of the constitutive binary systems using thermodynamic data from refs. [6,9]: (a) Bi-Sn system, (b) Bi-Zn system,

(c) Sn-Zn system.

Calculated liquidus projection of the ternary $\mathrm{Sn}-\mathrm{Bi}-\mathrm{Zn}$ system is shown in Fig. 2.

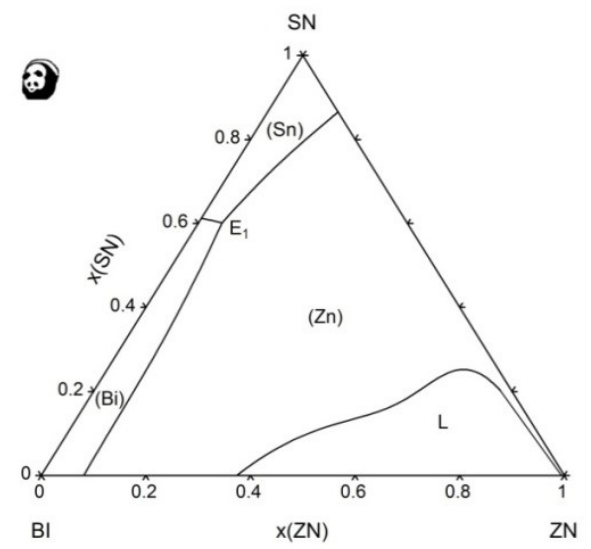

Fig. 2. Calculated liquidus projection of the ternary $S n-B i-Z n$ system using thermodynamic data from refs. [6,9] 
From the calculated plot of liquidus projection, it can be seen that there is one ternary eutectic reaction in this ternary system. Calculated temperature of the ternary eutectic reaction is $131.7^{\circ} \mathrm{C}$. Also, there are three primary crystallization fields of (Bi), (Sn) and (Zn) solid solution phases, and one region of liquid immiscibility spreading from the boundary Bi-Zn system.

\section{Results and Discussion}

\section{Microstructure Investigation}

Microstructure investigation of samples was performed using the SEM-EDS analysis. The energy-dispersive X-ray spectroscopy (EDS) was used to determine the overall chemical compositions of investigated samples and chemical compositions of co-existing phases.

The nominal and experimentally determined overall compositions of investigated samples are presented in Table 1.

Table 1 Results of EDS analysis

\begin{tabular}{|c|c|c|c|c|}
\hline Sample & \multirow{2}{*}{$\begin{array}{c}\text { Nominal } \\
\text { composition }\end{array}$} & \multicolumn{3}{|c|}{ Experimentally determined composition (at.\%) } \\
\cline { 3 - 5 } & (at.\%) & $\mathbf{S n}$ & $\mathbf{Z n}$ & $\mathbf{B i}$ \\
\hline 1 & & $81.4 \pm 0.6$ & $14.8 \pm 1.0$ & $3.8 \pm 0.4$ \\
\hline 2 & $\mathrm{Sn}_{80} \mathrm{Zn}_{16} \mathrm{Bi}_{4}$ & $80.8 \pm 0.6$ & $11.9 \pm 1.1$ & $7.3 \pm 0.4$ \\
\hline 3 & $\mathrm{Sn}_{80} \mathrm{Zn}_{12} \mathrm{Bi}_{8}$ & $90.7 \pm 0.7$ & $9.6 \pm 0.8$ & $9.7 \pm 0.5$ \\
\hline 4 & $\mathrm{Sn}_{80} \mathrm{Zn}_{10} \mathrm{Bi}_{10}$ & $80.3 \pm 0.6$ & $7.8 \pm 0.7$ & $11.9 \pm 0.4$ \\
\hline 5 & $\mathrm{Sn}_{80} \mathrm{Zn}_{8} \mathrm{Bi}_{12}$ & $80.2 \pm 0.6$ & $5.5 \pm 0.8$ & $14.3 \pm 0.5$ \\
\hline 6 & $\mathrm{Sn}_{80} \mathrm{Zn}_{6} \mathrm{Bi}_{14}$ & $80.2 \pm 0.6$ & $2.8 \pm 1.0$ & $17.0 \pm 0.3$ \\
\hline
\end{tabular}

It was determined that the microstructures of all six investigated alloys consist of $\mathrm{Sn}$ matrix (gray area), ( $\mathrm{Zn}$ ) solid solution (dark areas) and (Bi) solid solution (white areas) phases in the form of fine dispersed particles in the $\mathrm{Sn}$ matrix. The average chemical compositions of identified phases are shown in Table 2.

Table 2 Chemical compositions of co-existing phases determined by the EDS analysis

\begin{tabular}{|c|c|c|c|c|c|c|c|c|c|}
\hline Sample & \multicolumn{3}{|c|}{$\begin{array}{c}\text { (Sn)-Grey phase } \\
\text { (at.\%) }\end{array}$} & \multicolumn{3}{c|}{$\begin{array}{c}\text { (Bi)-White phase } \\
\text { (at.\%) }\end{array}$} & \multicolumn{3}{c|}{$\begin{array}{c}\text { (Zn)-Dark phase } \\
\text { (at.\%) }\end{array}$} \\
\cline { 2 - 11 } & $\mathrm{Sn}$ & $\mathrm{Zn}$ & $\mathrm{Bi}$ & $\mathrm{Sn}$ & $\mathrm{Zn}$ & $\mathrm{Bi}$ & $\mathrm{Sn}$ & $\mathrm{Zn}$ & $\mathrm{Bi}$ \\
\hline 1 & 97.4 & 1.4 & 1.2 & 1.5 & 0.4 & 98.1 & 2.5 & 97.0 & 0.5 \\
\hline 2 & 97.6 & 1.2 & 1.2 & 1.5 & 0.5 & 98.0 & 2.9 & 96.5 & 0.6 \\
\hline 3 & 97.4 & 1.0 & 1.6 & 1.6 & 0.2 & 98.2 & 3.1 & 96.3 & 0.6 \\
\hline 4 & 97.3 & 0.9 & 1.8 & 2.0 & 0 & 98.0 & 3.2 & 96.2 & 0.6 \\
\hline 5 & 97.8 & 0.4 & 1.8 & 1.7 & 0 & 98.3 & 3.6 & 95.8 & 0.6 \\
\hline 6 & 97.5 & 0 & 2.5 & 2.0 & 0 & 98.0 & 3.9 & 95.4 & 0.7 \\
\hline
\end{tabular}

The microstructures of two as-cast $\mathrm{Sn}-\mathrm{Bi}-\mathrm{Zn}$ alloys are shown in Fig. 3. 


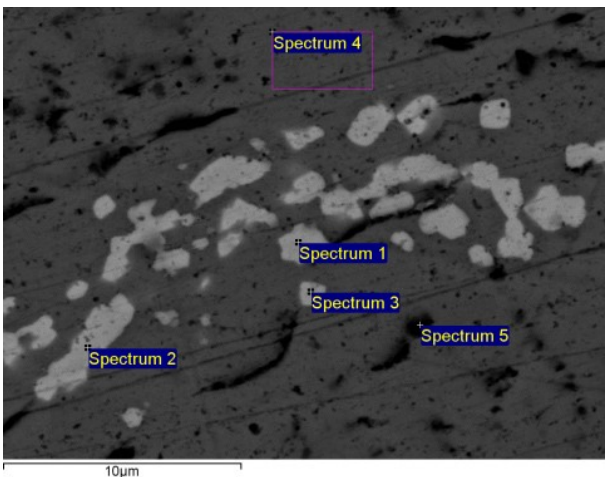

(a)

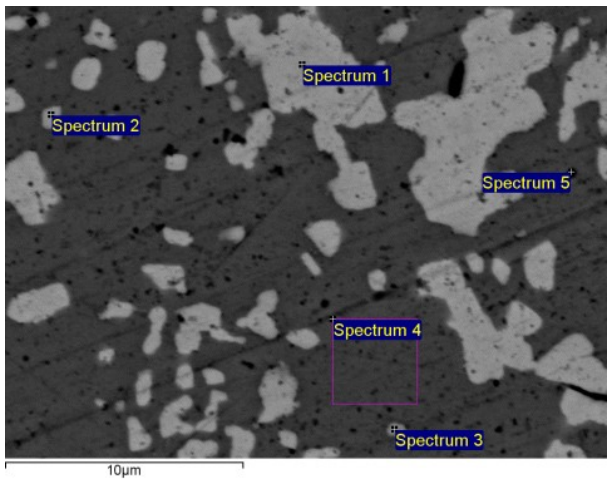

(b)

Fig. 3. Microstructures of the as-cast samples: (a) Sample 2 (Sn80.8-Zn11.9-Bi7.3); (b) Sample 6 (Sn80.2-Zn2.8-Bi17.0)

The experimentally obtained results of microstructure investigation were compared with the calculated phase equilibria. In order to obtained the coexisting phases for the investigating samples of the $\mathrm{Sn}-\mathrm{Bi}-\mathrm{Zn}$ ternary system at room temperature in equilibrium conditions, isothermal section of the $\mathrm{Sn}-\mathrm{Bi}-\mathrm{Zn}$ ternary system at $25{ }^{\circ} \mathrm{C}$ was calculated and shown in Fig. 4 together with the marked overall compositions of the investigated samples in this study.

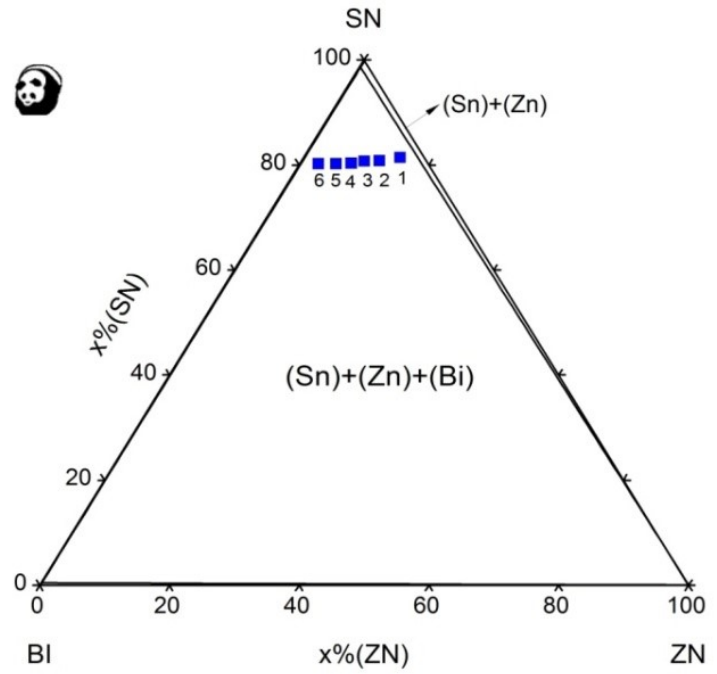

Fig. 4. Calculated equilibrium phase diagram of the ternary $\mathrm{Sn}-\mathrm{Bi}-\mathrm{Zn}$ system at $25^{\circ} \mathrm{C}$ with marked overall compositions of the investigated alloy samples 
According to the calculated phase diagram, the overall compositions of all six samples belong to the three-phase region: $(\mathrm{Bi})+(\mathrm{Sn})+(\mathrm{Zn})$ which is in agreement with the EDS results. In contrast to the calculated phase equilibria, the EDS results indicate that both $(\mathrm{Bi})$ and $(\mathrm{Zn})$ phases dissolve some amount of other elements. Accordingly, solubility of $\mathrm{Sn}$ in the (Bi) and $(\mathrm{Zn})$ solid solutions is determined to be 2 and 4 at.\%, respectively.

However, the accuracy of experimentally determined solubility of $\mathrm{Sn}$ in the (Bi) and $(\mathrm{Zn})$ phases is negatively influenced by the small grain sizes of the $(\mathrm{Bi})$ and $(\mathrm{Zn})$ phases in the matrix phase.

\section{Results of Thermal Analysis}

Experimental determination the phase transition temperatures of investigated samples was done using the differential scanning calorimetry (DSC). Solidus temperatures and temperatures of invariant reactions were taken from the extrapolated peak onset, and liquidus temperatures were taken from the peak maximum on heating [11]. Beside solidus and liquidus temperatures additional phase transition at $193.5{ }^{\circ} \mathrm{C}$ was identified only for the sample 1 . According to the calculated results it corresponds to the end of melting of the (Sn) phase.

Measured phase transition temperatures obtained during the second heating run are presented in Table 3.

Table 3 DSC results for the investigated alloys in the Sn-Bi-Zn ternary system.

\begin{tabular}{|l|c|c|c|}
\hline \multirow{2}{*}{ Sample } & \multicolumn{3}{|c|}{ Phase transformation temperature $\left({ }^{\circ} \mathbf{C}\right)$} \\
\cline { 2 - 4 } & Solidus & Other & Liquidus \\
\hline $1\left(\mathrm{Bi}_{3.8} \mathrm{Sn}_{81.4} \mathrm{Zn}_{14.8}\right)$ & 158.2 & 193.5 & 214.3 \\
\hline $2\left(\mathrm{Bi}_{7.3} \mathrm{Sn}_{80.8} \mathrm{Zn}_{11.9}\right)$ & 131.1 (eutectic reaction) & - & 186.5 \\
\hline $3\left(\mathrm{Bi}_{9.7} \mathrm{Sn}_{80.7} \mathrm{Zn}_{9.6}\right)$ & 132.5 (eutectic reaction) & - & 185.2 \\
\hline $4\left(\mathrm{Bi}_{11.9} \mathrm{Sn}_{80.3} \mathrm{Zn}_{7.8}\right)$ & 132.7 (eutectic reaction) & - & 178.4 \\
\hline $5\left(\mathrm{Bi}_{14.3} \mathrm{Sn}_{80.2} \mathrm{Zn}_{5.5}\right)$ & 131.3 (eutectic reaction) & - & 176.4 \\
\hline $6\left(\mathrm{Bi}_{17.0} \mathrm{Sn}_{80.2} \mathrm{Zn}_{2.8}\right)$ & 131.3 (eutectic reaction) & - & 183.0 \\
\hline
\end{tabular}

Having in mind that in the $\mathrm{Sn}-\mathrm{Bi}-\mathrm{Zn}$ ternary system alloys were investigated in this study in the as-cast state (fast cooling rate), it is valuable, beside the equilibrium calculation, to perform a simulation of non-equilibrium solidification according to the Scheil model for comparison. Fig. 5 shows a mutual comparison between the experimental result (DSC curve), calculated equilibrium and non-equilibrium solidification path for sample $2\left(\mathrm{Bi}_{7.3} \mathrm{Sn}_{80.8} \mathrm{Zn}_{11.9}\right)$. 


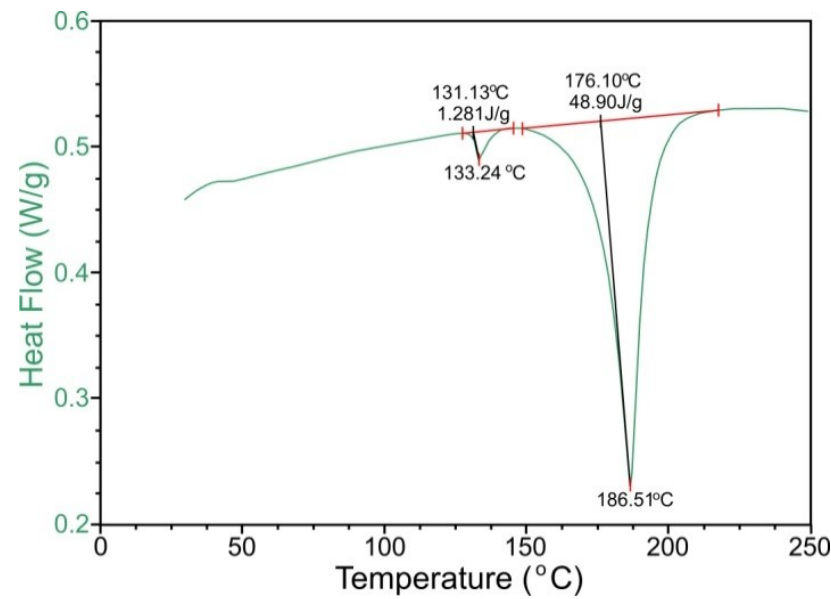

(a)

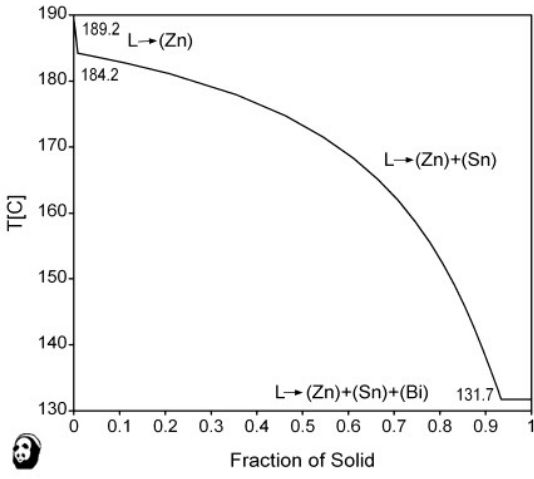

(b)

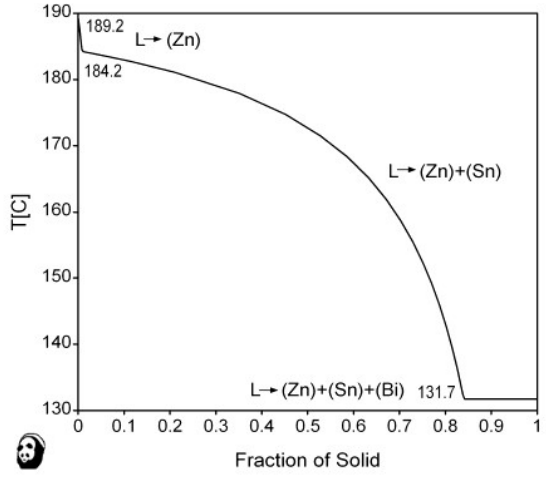

(c)

Fig. 5. Comparison between the experimental results and calculated solidification paths for sample 2 (Bi ${ }_{7.3} S_{80.8} Z n_{11.9}$ ): (a) DSC heating curve; (b) Equilibrium model (Lever rule); (c) Non-equilibrium model (Scheil model)

Fig. 5 reveals a good agreement between the experimental results, equilibrium and non-equilibrium solidification models for sample 2. It can be seen that according to both solidification models solidification of the alloy starts at $189.2{ }^{\circ} \mathrm{C}$ with the primary crystallization of $(\mathrm{Zn})$ phase from the melt (liquidus temperature). Simultaneous crystallization of $(\mathrm{Zn})$ and $(\mathrm{Sn})$ phases from the melt starts at $184.2^{\circ} \mathrm{C}$ according to both solidification models.

In accordance with the both solidification models, solidification of alloy 2 finishes at $131.7{ }^{\circ} \mathrm{C}$ (solidus temperature) with appearance of the ternary eutectic reaction $\mathrm{L} \leftrightarrow(\mathrm{Zn})+(\mathrm{Sn})+(\mathrm{Bi})$. 
From the DSC curve presented in Fig.5a, it can be seen that the temperature of extrapolated onset of the first peak $\left(131.1^{\circ} \mathrm{C}\right)$, obtained on heating, is in very good agreement with the calculated temperature of the ternary eutectic reaction $\left(131.7^{\circ} \mathrm{C}\right)$. Maximum temperature of the second peak obtained on heating $186.5^{\circ} \mathrm{C}$ represents the alloy liquidus temperature, and is in reasonable agreement with the results of solidification simulation.

Fig. 6 shows a comparison between the experimental data and calculated solidification paths according to the equilibrium and non-equilibrium models for sample $4\left(\mathrm{Bi}_{11.9} \mathrm{Sn}_{80.3} \mathrm{Zn}_{7.8}\right)$.

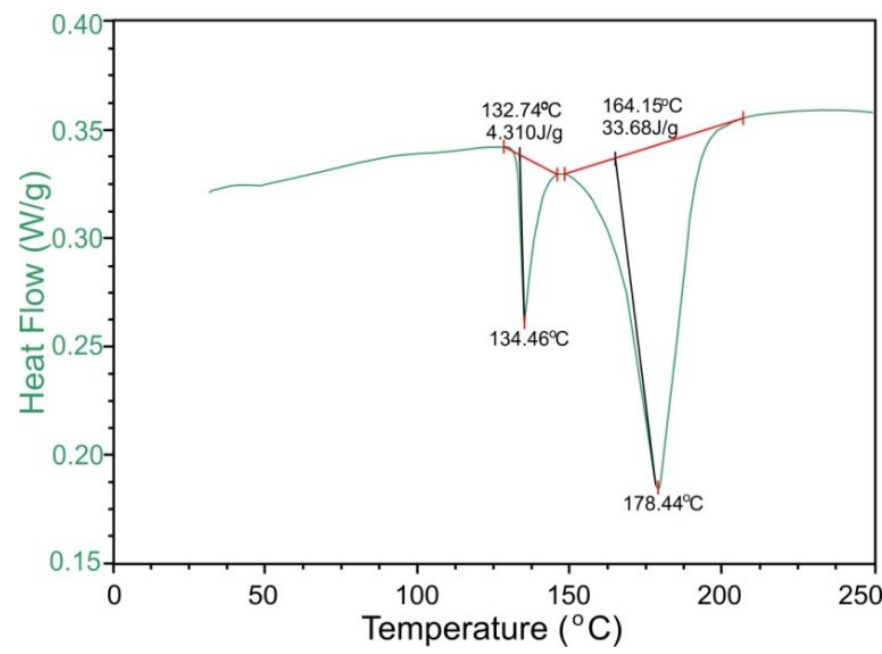

(a)

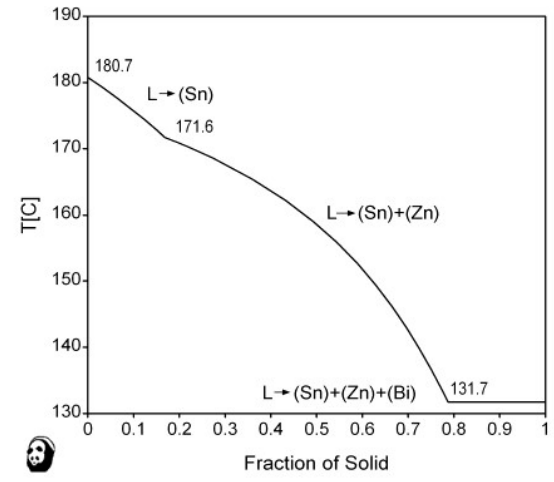

(b)

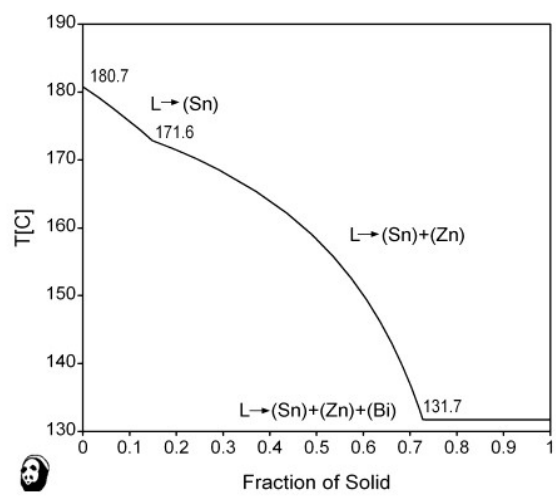

(c)

Fig. 6. Comparison between the experimental results and calculated solidification paths for sample 4 (Bi $\left.{ }_{11.9} S n_{80.3} Z n_{7.8}\right)$ : (a) DSC heating curve; (b) Equilibrium model (the Lever rule); (c) Non-equilibrium model (the Scheil model) 
As in the case of sample 2, there is a good mutual agreement between the calculation and experimental results for the sample 4. In Fig.6, the first peak obtained on heating represents the ternary eutectic reaction $\mathrm{L} \leftrightarrow(\mathrm{Zn})+(\mathrm{Sn})+(\mathrm{Bi})$. Experimentally obtained temperature of this invariant reaction is determined as the extrapolated onset temperature of this peak $\left(132.7^{\circ} \mathrm{C}\right)$. Maximum temperature of the second larger peak $\left(178.4{ }^{\circ} \mathrm{C}\right)$ represents the end of $(\mathrm{Sn})$ melting, i.e. liquidus temperature for sample 4. This measured value is in a good agreement with the corresponding calculated liquidus temperature for sample $4\left(180.7^{\circ} \mathrm{C}\right)$ shown in Figs. $6 \mathrm{~b}$ and $6 \mathrm{c}$.

All experimentally determined phase transformation temperatures (DSC) from Table 3 are shown on calculated vertical section with 80 at.\% Sn (Fig. 7) for comparison and good agreement between the measured temperatures of phase transitions, and related calculated values can be noticed.

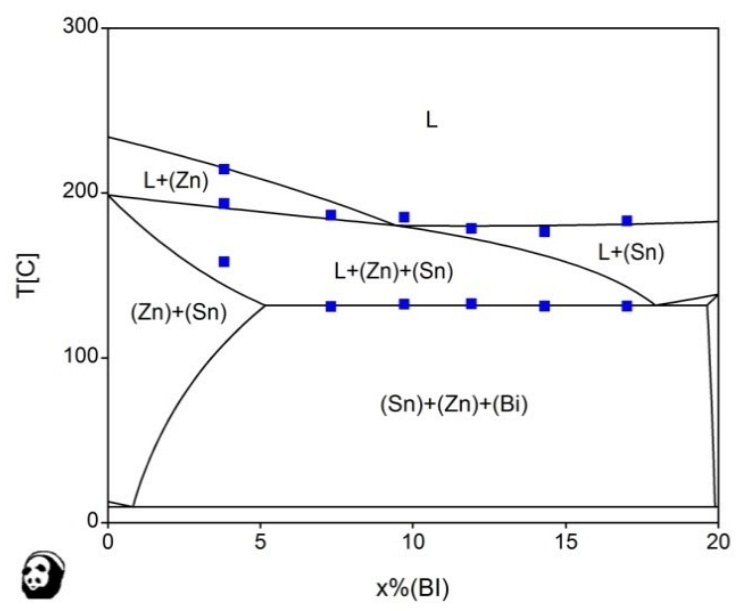

Fig. 7. Calculated vertical section of the Sn-Bi-Zn ternary system with 80 at.\% of Sn compared to the DSC results from this work. Temperatures measured by DSC on heating are denoted by blue squares

\section{Conclusion}

Microstructure and soldification proceses of Sn-rich alloys of the ternary $\mathrm{Sn}-\mathrm{Bi}$ $\mathrm{Zn}$ systems were studied in this work. The six investigated alloys with nearly constant content of Sn (80 at.\%) were experimentally investigated using SEM-EDS and DSC methods.

Identification the co-existing phases in the as-cast samples was performed using the SEM-EDS analysis. It was determined that microstructures of all six investigated samples include ( $\mathrm{Sn}),(\mathrm{Bi})$ and $(\mathrm{Zn})$ solid solution phases.

The phase transition temperatures were measured using DSC. Based on the obtained results liquidus and solidus temperatures of the investigated alloys were determined. Appearance of the ternary eutectic reaction $\mathrm{L} \rightarrow(\mathrm{Zn})+(\mathrm{Sn})+(\mathrm{Bi})$ was also detected. Measured temperature of the ternary eutectic reaction is in a very good agreement with calculated results. 
All experimental results were compared with the results of thermodynamic calculation based on the optimized thermodynamic parameters taken from literature. Calculated solidification paths using equilibrium and non-equilibrium Scheil models were compared with the results of DSC measurements, and a reasonable mutual agreement was found.

The results presented in this study are contribution to better understanding the microstructural and thermal properties of the Sn-rich ternary $\mathrm{Sn}-\mathrm{Bi}-\mathrm{Zn}$ alloys that are important for further development of the lead-free solder materials.

\section{Acknowledgement}

D. Manasijević and D. Minić acknowledge the support of the Ministry of Education, Science and Technological Development of the Republic of Serbia, project No. OI172037.

\section{References}

[1] C. M. Chen, C. H. Chen: J. Electron. Mater. 3610 (2007) 1363-1371.

[2] C. M. L. Wu, C. M. T. Law, D. Q. Yu, L. Wang: J. Electron. Mater. 322 (2003) 63-69.

[3] R. Islam, B. Wu, M. Alam, Y. Chan, W. Jillek: J. Alloy. Compd. 392 (2005) 149158 ,

[4] M. Ramani, A. B. Ismail, Z. A. Ahmad, T. Ariga, L.B. Hussain: J. Teknologi, 46 (2007) 1-14

[5] M.H. Braga, J. Vizdal, A. Kroupa, J. Ferreira, D. Soares, L.F. Malheiros: Calphad, 31 (4) (2007) 468-478.

[6] J. Vizdal, M. H. Braga, A. Kroupa, K. W. Richter, D. Soares, L. F. Malheiros, J. Ferreira: Calphad, 31 (2007) 438-448.

[7] N. Saunders, A.P. Miodownik: CALPHAD (A Comprehensive Guide), Elsevier, London, 1998.

[8] H. L. Lukas, S. G. Fries, B. Sundman: Computational Thermodynamics, Cambridge University Press, Cambridge, UK, 2007.

[9] A. Kroupa, A. T. Dinsdale, A. Watson, J. Vrestal, J. Vízdal, A. Zemanova: JOM 59 (7) (2007) 20-25.

[10] W. Cao, S.L. Chen, F. Zhang, K. Wu, Y. Yang, Y. A. Chang, R. Schmid-Fetzer, W. A. Oates: Calphad, 33 (2009) 328-342.

[11] W.J. Boettinger, U.R. Kattner, K.-W. Moon, J.H. Perepezko: DTA and Heat-flux DSC Measurements of Alloy Melting and Freezing, NIST Special Publication 96015, Washington, 2006. 